\title{
The Analgesic Effects of Bupivacaine and Magnesium Sulfate Combination, Bupivacaine, and Adrenaline Combination and Bupivacaine Alone on Post-cesarean Section Pain: A Randomized Clinical Trial
}

\author{
Zinatossadat Bouzari' ${ }^{1}$, Seyedeh Rabeeh Rouhani ${ }^{2}$, Ebrahim Alijanpour ${ }^{3^{*}}{ }^{\mathbb{D}}$, Shahla Yazdani ${ }^{4}$, Bahman Hasannasab ${ }^{3}$, \\ Karimollah Hajian-Tilaki ${ }^{5}$
}

\begin{abstract}
Objectives: The present study was performed to compare the analgesic effects of bupivacaine and magnesium sulfate combination on post-cesarean (C) section pain.

Materials and Methods: The present single-blind randomized clinical trial was conducted on $160 \mathrm{C}$-section candidates. The participants were randomly divided into four groups. When the fascia healed, the first group received $20 \mathrm{~mL}$ of $0.25 \%$ bupivacaine and the second group received $20 \mathrm{~mL}$ of $0.25 \%$ bupivacaine combined with subcutaneous adrenaline. In addition, both groups received $50 \mathrm{~mL}$ of intravenous normal saline. Further, the third group received subcutaneous bupivacaine and $50 \mathrm{mg} / \mathrm{kg}$ of magnesium sulfate and the fourth group received subcutaneous and intravenous normal saline as a placebo. The pain intensity was assessed 2, $6,12,18$, and 24 hours after spinal anesthesia using the visual analogue scale (VAS) for pain. The dose of pethidine (as a standard analgesic) and hemodynamic parameters (i.e., heart rate [HR] and blood pressure [BP]) was recorded as well. The obtained data were then analyzed utilizing ANOVA, Tukey's HSD, and repeated measures ANOVA tests.

Results: The intensity of pain and the dose of pethidine decreased significantly in the combination of bupivacaine with magnesium compared to the other groups at all times $(P<0.001)$. However, diastolic BP significantly increased in the bupivacaine + adrenaline group in comparison with the other groups $(P=0.02)$.

Conclusions: Overall, bupivacaine combination with magnesium sulfate is suitable for controlling post-cesarean section pain. Keywords: Pain, Magnesium sulfate, Adrenaline, Bupivacaine, Cesarean section
\end{abstract}

\section{Introduction}

Cesarean delivery is one of the most common surgeries across the world (1). The cesarean delivery rate has shown a steady rise from $35 \%$ in 2000 to $45 \%$ in 2005 in Iran (2). According to the latest statistics published by the World Health Organization, Iran ranks first regarding cesarean delivery in the region and has the second place in the world (3). Postoperative pain delays walking, extends hospital stays, increases the incidence of vein thrombosis, and eventually, leads to patient dissatisfaction (4). Pain treatment after the cesarean section is different from general surgery. In particular, a woman needs to recover faster to take care of her baby (5). Therefore, post-cesarean section pain control is a critical issue that leads to a more favorable experience of childbirth for mothers (6).

Several studies are currently being performed on the methods that can help reduce and relieve post-operative pain $(5,7,8)$. These studies have extensively examined the impact of effective pain relief in the first hours after cesarean section $(6,7,9)$. Postoperative pain is often improperly controlled with opioids even when the patient is resting. There has been growing interest in recent years regarding the use of topical anesthetics for postoperative pain relief due to the analgesic properties of these substances and their lack of adverse effects unlike the case of opioids (10).

The subcutaneous injection of bupivacaine and epinephrine with bupivacaine in place of incisions during surgery reduces pain and the amount of diclofenac in the early hours after cesarean section $(11,12)$. The previous study showed that continuous intravenous infusion of magnesium reduces pain during and after surgery. It also reduces the need for analgesic drugs (13). In another study, an inverse relationship was found between the severity of pain with different painful medical and surgical conditions and the serum magnesium levels (14). However, other studies obtained contradictory results on the use of topical anesthesia after cesarean section (7,9,15-17). In this study, 
it was hypothesized that the subcutaneous infiltration of bupivacaine with I.V magnesium has the potential to be effective in reducing post-cesarean section pain compared with bupivacaine alone or with adrenaline. Therefore, the present study strove to compare the analgesic effects of bupivacaine and magnesium sulfate combination, bupivacaine and adrenaline combination, and bupivacaine alone on post-cesarean section pain.

Cesarean delivery has higher maternal surgical risks for the cesarean and subsequent pregnancies compared with spontaneous vaginal birth. This is balanced against lower rates of perineal injury and short-term pelvic floor disorder. However, cesarean delivery offers lower rates of initial respiratory difficulties for neonates (18). Women with one or more prior cesarean deliveries are at greater risk for subsequent placental disorders including placenta previa, abruption, or morbidity adherent placenta (18).

The reasons for persistently significant cesarean rates are not completely understood, but some explanations can be provided in this regard as follows:

1. Women are having fewer children; thus a greater percentage of births are among nulliparous who are at increased risk for cesarean delivery.

2. The average maternal age is rising and older women, especially nulliparous, are at a higher risk of cesarean delivery.

3. Obesity, which is a cesarean delivery risk, reaches epidemic proportions.

4. Elective cesarean deliveries are increasing because of maternal request (18).

The aim of the study is pain relief sufficient medical indication for its provision.

\section{Materials and Methods}

The single-blind randomized clinical trial was conducted under the registration code of IRCT2015090723926N1 in 2015 and was approved by the Regional Committee for Medical Research Ethics at Babol University of Medical Sciences. Written informed consent was obtained from all patients. This study was carried out in accordance with the Code of Ethics of the World Medical Association (Declaration of Helsinki). The study participants consisted of 160 pregnant women who were candidates for elective cesarean section and referred to Ayatollah Rouhani Hospital in Babol, Iran. The flowchart of patient enrolment is shown in Figure 1.

Assuming $\mathrm{SD}=1$ (VAS), pain with $80 \%$ test power, and 95\% confidence level, the required size to identify the difference $\mathrm{d}=1^{\text {scale }}$

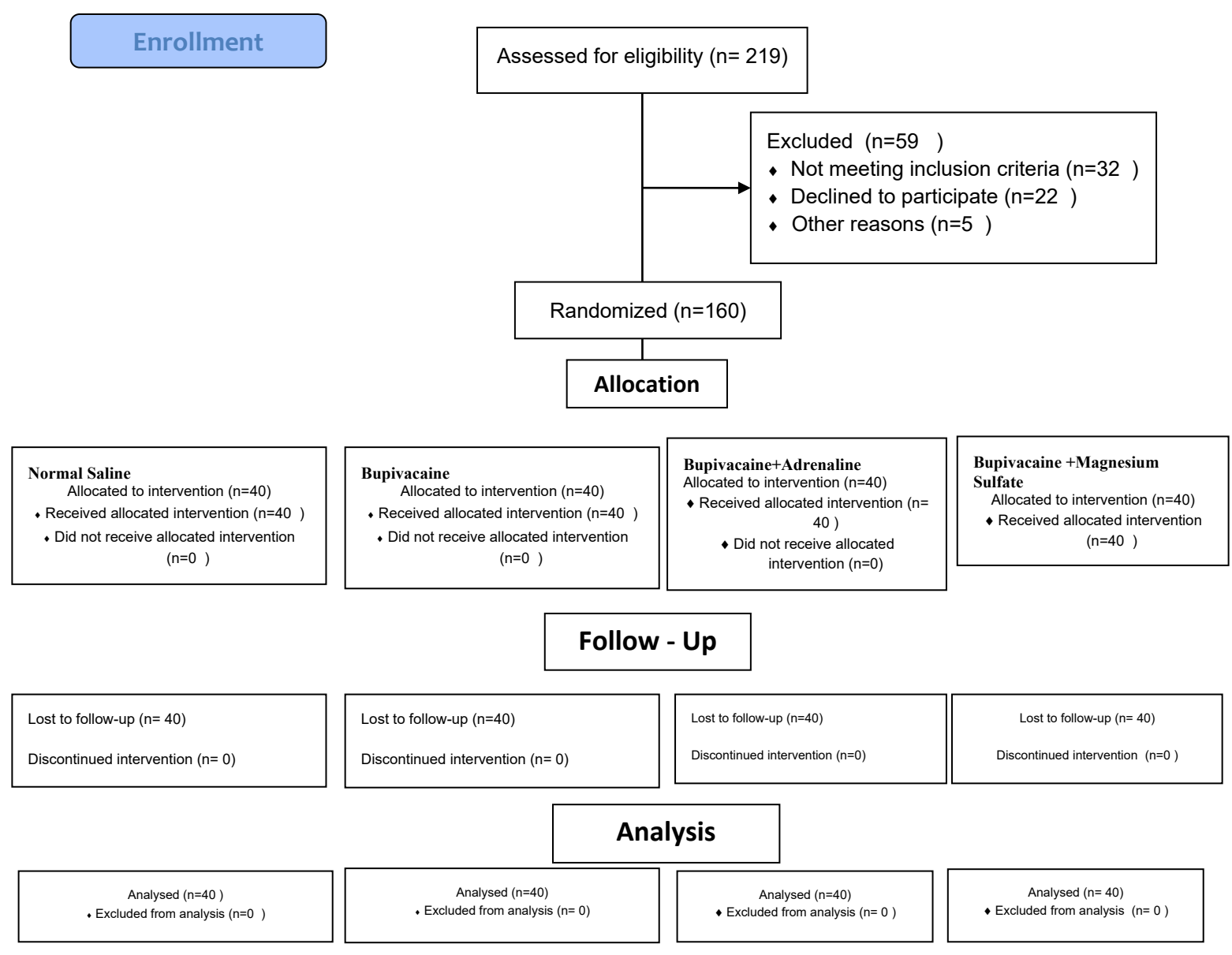

Figure 1. Flowchart of Patient Enrollment, Allocation, Follow-up, and Analysis. 
$\mathrm{N}=\frac{2\left(Z_{1}-\frac{\alpha}{2}+Z \beta\right)^{2} S D^{2}}{d^{2}}=\frac{2(1.96+0.84)^{2} 1.5^{2}}{1^{2}}=40$

Women were included in each group and the total sample size was 160 cases.

The allocated sample size in four groups under study with an equal sample of 40 was able to detect a standardized effect size of 0.6 between the two groups in multiple comparisons with $80 \%$ power and $95 \%$ confidence level. The inclusion criteria consisted of having a term pregnancy, having a singleton pregnancy, being classified as ASA I or II, being $160-170 \mathrm{~cm}$ in height, and weighing 70-100 $\mathrm{kg}$ by the end of the pregnancy. In addition, the exclusion criteria were a history of known allergies to topical amide anesthetics (e.g., bupivacaine and lidocaine), magnesium sulfate, and epinephrine, a history of using opioids, coagulation disorders, a history of seizures, and cardiovascular diseases. Further, the other exclusion criteria included psychiatric disorders, asthma and chronic obstructive pulmonary disease, severe intrahepatic cholestasis of pregnancy, renal and liver diseases, atrioventricular block, a history of using calcium channel blockers, postoperative atony, and the duration of surgery longer than 1.5 hours.

After putting the patients on the operating room bed, they underwent heart rate (HR), peripheral oxygen saturation, non-invasive blood pressure (BP), and cardiac monitoring.

Prior to the induction of analgesia, $5-7 \mathrm{~mL} / \mathrm{kg}$ of Ringer's lactate solution was intravenously infused and all patients underwent spinal anesthesia with the same method (the same type and dose of the drug). All the C-section candidates were first placed in a sitting position and an anesthesiologist injected $12.5 \mathrm{mg}$ of $0.5 \%$ bupivacaine (made by AstraZeneca plc) into their lumbar intervertebral space (at $\mathrm{L}_{4-5}$ or $\mathrm{L}_{3-4}$ ) with a 25-gauge spinal needle (made by B-Braun Medical Inc.) after prepping and draping. The surgery began once the sensory block reached the $\mathrm{T}_{5-\mathrm{T} 6}$ dermatome. In cases of inadequate sensory block, the patient underwent general anesthesia and was excluded from the study.

Furthermore, block randomization was used to allocate an equal sample size for each group. Thus, the participants were randomly divided into groups one to four by the order of their entrance in the operating room.

Group 1: Bupivacaine $\left(\mathrm{N}_{\mathrm{B}}=40\right)$ : At the beginning of the surgery, $50 \mathrm{~mL}$ of normal saline was injected intravenously over 15 minutes. After the fascia healed, $10 \mathrm{~mL}$ of $0.5 \%$ bupivacaine, increased to $20 \mathrm{~mL}$ with the addition of 10 $\mathrm{mL}$ of normal saline, was injected into the subcutaneous fat on both sides of the incision in 10 separate injections of $2 \mathrm{~mL}$ within equal intervals.

Group 2: Bupivacaine and adrenaline combination $\left(\mathrm{N}_{\mathrm{BA}}=40\right)$ : At the beginning of the surgery, $50 \mathrm{~mL}$ of $0.9 \%$ normal saline was injected intravenously over 15 minutes. Following the fascia healed, a combination of 0.1 $\mathrm{mL}$ of $1: 1000$ adrenaline and $10 \mathrm{~mL}$ of $0.5 \%$ bupivacaine, increased to $20 \mathrm{~mL}$ with the addition of normal saline, was injected exactly as in the previous group.

Group 3: Bupivacaine and magnesium sulfate combination $\left(\mathrm{N}_{\mathrm{BM}}=40\right)$ : At the beginning of the surgery, $50 \mathrm{mg} / \mathrm{kg}$ of $50 \%$ magnesium sulfate (3-4 g), increased to $50 \mathrm{~mL}$ with the addition of normal saline, was injected intravenously over 15 minutes. After the fascia healed, $10 \mathrm{~mL}$ of $0.5 \%$ bupivacaine, increased to $20 \mathrm{~mL}$ with the addition of normal saline, was injected exactly as in the previous group.

Group 4: Normal saline $\left(\mathrm{N}_{\mathrm{S}}=40\right)$ : At the beginning of the surgery, $50 \mathrm{~mL}$ of normal saline was injected intravenously over 15 minutes. After the fascia healed, $20 \mathrm{~mL}$ of normal saline was injected into the subcutaneous fat exactly as in the previous groups. All patients were blinded to their group assignment.

Before the surgery, the patients were instructed on the function of the visual analogue scale (VAS) for pain. Thus, the researchers showed them a $10-\mathrm{cm}$ ruler graded from 0 to 10 and explained that selecting 'no pain' and 'the severest pain' are displayed on the ruler by 0 and 10 , respectively. The patients specified their intensity of pain on the ruler and their pain was then calculated based on the specified number. The intensity of pain VAS varied from 0 to 10 . The 0 showed no pain while 10 represented the highest feeling of pain. Hemodynamic changes in BP and HR were measured 2, 6, 12, 18, and 24 hours after spinal anesthesia. All the patients received $0.5 \mathrm{mg} / \mathrm{kg}$ of intramuscular pethidine (max. $0.50 \mathrm{mg} / \mathrm{kg}$ ) 2 hours after spinal anesthesia since their spinal drug was no longer effective. About $0.25 \mathrm{mg} / \mathrm{kg}$ of pethidine (max. $30 \mathrm{mg}$ ) was administered and the total analgesic dose administered in a period of 24 hours was recorded if the VAS score was calculated as 4 or above $6,12,18$, and 24 hours after spinal anesthesia or if the patient expressed pain and asked for an analgesic. The data were analyzed by SPSS software (version 18.0) using the repeated measures ANOVA and Tukey's pair comparison. The $P$ values $<0.05$ were considered statistically significant.

The allowed dosage of bupivacaine and pethidine is 2-3 $\mathrm{mg} / \mathrm{kg}$ (19) and about $0.5-1 \mathrm{mg} / \mathrm{kg}$, respectively (20).

\section{Results}

The demographic details of the participants are provided in Table 1 . The mean age $( \pm S D)$ of the participants was $30.61 \pm 4.5$ years. In addition, their mean pre-pregnancy body mass index (BMI) was $26.6 \pm 3.1 \mathrm{~kg} / \mathrm{m}^{2}$ and their post-pregnancy BMI was $30.59 \pm 3.1 \mathrm{~kg} / \mathrm{m}^{2}$. There were no differences between the groups in terms of any of the examined variables $(P>0.05)$.

According to the ANOVA (Table 2), the intensity of pain significantly decreased in the group receiving bupivacaine and magnesium sulfate combination compared to all the other groups at all times $(P<0.001)$. Further, the intensity 
Table 1. The Baseline Demographic Characteristics and Anthropometric Measures According to Study Groups

\begin{tabular}{|c|c|c|c|c|c|}
\hline Variable & $\begin{array}{l}\text { Normal Saline } \\
\text { Mean } \pm \text { SD }\end{array}$ & $\begin{array}{l}\text { Bupivacaine } \\
\text { Mean } \pm \text { SD }\end{array}$ & $\begin{array}{c}\text { Bupivacaine+Adrenaline } \\
\text { Mean } \pm \text { SD }\end{array}$ & $\begin{array}{c}\text { Bupivacaine + Magnesium Sulfate } \\
\text { Mean } \pm \text { SD }\end{array}$ & $P$ Value \\
\hline Age (y) & $29.6 \pm 4.3$ & $31.9 \pm 4.2$ & $29.9 \pm 4.6$ & $30.8 \pm 4.5$ & 0.093 \\
\hline Pre-pregnancy weight (kg) & $72.2 \pm 9.2$ & $69.4 \pm 7.5$ & $68.1 \pm 7.1$ & $70.2 \pm 9.3$ & 0.195 \\
\hline Post-pregnancy weight (kg) & $82.4 \pm 9.6$ & $79.3 \pm 7.0$ & $78.4 \pm 7.6$ & $81.0 \pm 9.9$ & 0.177 \\
\hline Height (cm) & $162.0 \pm 2.95$ & $161.7 \pm 2.7$ & $162.0 \pm 3.8$ & $162.2 \pm 3.2$ & 0.951 \\
\hline Gravidity & $2.4 \pm 0.71$ & $2.6 \pm 1$ & $2.4 \pm 0.9$ & $2.4 \pm 1$ & 0.59 \\
\hline Parity & $1.2 \pm 0.5$ & $1.2 \pm 0.5$ & $1.0 \pm 0.5$ & $1.1 \pm 0.6$ & 0.59 \\
\hline Pre-pregnancy BMI & $27.5 \pm 3.5$ & $26.5 \pm 2.8$ & $25.9 \pm 2.7$ & $26.6 \pm 3.3$ & 0.166 \\
\hline Post-pregnancy BMI & $31.3 \pm 3.6$ & $30.3 \pm 2.5$ & $29.8 \pm 2.4$ & $30.7 \pm 3.5$ & 0.149 \\
\hline \multicolumn{6}{|l|}{ Education } \\
\hline Above high school (\%) & 27.5 & 38.5 & 25 & 43.9 & 0.215 \\
\hline High school or below (\%) & 72.5 & 61.5 & 75 & 56.1 & 0.215 \\
\hline
\end{tabular}

SD: standard deviation; BMI: body mass index.

Table 2. Comparison of Pain Intensity During Different Time points Between and Within Groups

\begin{tabular}{lcccc}
\hline $\begin{array}{l}\text { Hours Since } \\
\text { Surgery }\end{array}$ & $\begin{array}{c}\text { Normal Saline } \\
\text { Mean } \pm \text { SD }\end{array}$ & $\begin{array}{c}\text { Bupivacaine } \\
\text { Mean } \pm \text { SD }\end{array}$ & $\begin{array}{c}\text { Bupivacaine+Adrenaline } \\
\text { Mean } \pm \text { SD }\end{array}$ & $\begin{array}{c}\text { Bupivacaine +Magnesium Sulfate } \\
\text { Mean } \pm \text { SD }\end{array}$ \\
\hline 2 & $8.03 \pm 0.83$ & $7.31 \pm 0.97$ & $6.48 \pm 1.08$ & $4.71 \pm 1.20$ \\
6 & $7.70 \pm 0.82$ & $6.74 \pm 0.91$ & $5.78 \pm 0.92$ & $4.17 \pm 1.13$ \\
12 & $7.00 \pm 1.15$ & $5.85 \pm 0.81$ & $4.58 \pm 0.74$ & $3.51 \pm 0.67$ \\
18 & $5.83 \pm 1.37$ & $4.36 \pm 0.90$ & $3.88 \pm 0.75$ & $<0.001$ \\
24 & $4.72 \pm 1.63$ & $3.56 \pm 0.50$ & $3.20 \pm 0.60$ & $<.73 \pm 0.89$ \\
$P^{a}$ & $<0.001$ & $<0.001$ & $<0.001$ & $<0.001$ \\
\hline
\end{tabular}

${ }^{a}$ Repeated measures ANOVA; ${ }^{b}$ ANOVA.

of pain significantly decreased between the group receiving bupivacaine and adrenaline combination and the groups receiving bupivacaine or normal saline. This intensity also differed between the bupivacaine group and the normal saline group $(P<0.001)$. Based on the results of Tukey's post hoc HSD test, the intensity of pain did not differ significantly between the bupivacaine group and the bupivacaine and adrenaline combination group 18 and 24 hours after spinal anesthesia $(P=0.38$ and $P=0.148$, respectively). However, the difference was significant at all the other times.

As shown in Table 3, the dose of pethidine used 6, 12, 18 , and 24 hours after spinal anesthesia significantly decreased in the bupivacaine and magnesium sulfate combination group compared to all the other groups $(P<$ 0.001). The results of Tukey's post-hoc HSD test indicated that the dose of pethidine used 18 and 24 hours after spinal anesthesia did not differ significantly between the bupivacaine group and the bupivacaine and adrenaline combination group ( $P=0.14$ and $P=0.38$, respectively). The groups did not differ significantly from each other in terms of their mean systolic BP after spinal anesthesia $(P>0.05$, Figure 2). Based on the results of the oneway ANOVA, 2 hours after spinal anesthesia, the mean diastolic BP significantly increased in the bupivacaine and adrenaline combination group compared to all the other groups $(P=0.02$, Figure 3$)$.
According to Tukey's post-hoc HSD test, 2 hours after spinal anesthesia, the diastolic BP differed significantly between the bupivacaine and adrenaline combination group and the normal saline group $(P=0.048)$.

\section{Discussion}

The intensity of pain was measured using the VAS and the dose of postoperative pethidine administration was significantly lower in the bupivacaine and magnesium sulfate combination group compared to all the other groups. In a study by Eldaba et al, subcutaneous infiltration with a combination of bupivacaine and magnesium sulfate 24 hours after surgery resulted in a significant decrease in the intensity of pain and the dose of analgesics administered in the hours following the surgery compared to when the patients were receiving only bupivacaine or only normal saline (21). Tauzin-Fin et al also found that the infiltration of the incision site with a combination of bupivacaine and magnesium sulfate is effective in reducing the intensity of pain and the dose of analgesics used after the surgery (22), which is consistent with the results of the present study. In another study by Lee et al, the administration of a combination of bupivacaine and magnesium sulfate during surgery reduced the intensity of pain in the first 12 hours after the surgery, which is also in line with the findings of the present study. However, no significant differences were observed between this group and the 
Table 3. Comparison of Pethidine Dose During Different Time points Between and Within Groups

\begin{tabular}{|c|c|c|c|c|c|}
\hline \multirow[b]{2}{*}{ Hours Since Surgery } & \multicolumn{4}{|c|}{ Group } & \multirow[b]{2}{*}{$P^{b}$} \\
\hline & $\begin{array}{l}\text { Normal Saline }(\mathrm{mg}) \\
\text { Mean } \pm \text { SD }\end{array}$ & $\begin{array}{l}\text { Bupivacaine }(\mathrm{mg}) \\
\text { Mean } \pm \text { SD }\end{array}$ & $\begin{array}{c}\text { Bupivacaine } \\
+ \text { Adrenaline }(\mathrm{mg}) \\
\text { Mean } \pm \text { SD }\end{array}$ & $\begin{array}{c}\text { Bupivacaine }+ \text { Magnesium } \\
\text { Sulfate }(\mathrm{mg}) \\
\text { Mean } \pm \text { SD }\end{array}$ & \\
\hline 6 & $25.0 \pm 0.0$ & $24.3 \pm 4.0$ & $23.7 \pm 5.5$ & $7.9 \pm 11.8$ & $<0.001$ \\
\hline 12 & $16.4 \pm 11.9$ & $25.0 \pm 0.0$ & $15 \pm 12.4$ & $1.8 \pm 6.6$ & $<0.001$ \\
\hline 18 & $21.9 \pm 8.4$ & $9.0 \pm 12.2$ & $5.0 \pm 10.1$ & $0.6 \pm 3.9$ & $<0.001$ \\
\hline 24 & $6.2 \pm 10.7$ & 0 & 0 & 0 & $<0.001$ \\
\hline$P^{a}$ & $<0.001$ & $<0.001$ & $<0.001$ & $<0.001$ & \\
\hline
\end{tabular}

${ }^{\text {a }}$ Repeated measures ANOVA; ${ }^{\mathrm{b}}$ ANOVA.

group receiving normal saline in terms of the intensity of pain 24 hours after the surgery. Moreover, the analgesic doses used 4, 8, 12, and 24 hours after the surgery did not differ significantly between the cases and the controls. Contrarily, in the present study, a significant difference was observed between the group receiving bupivacaine

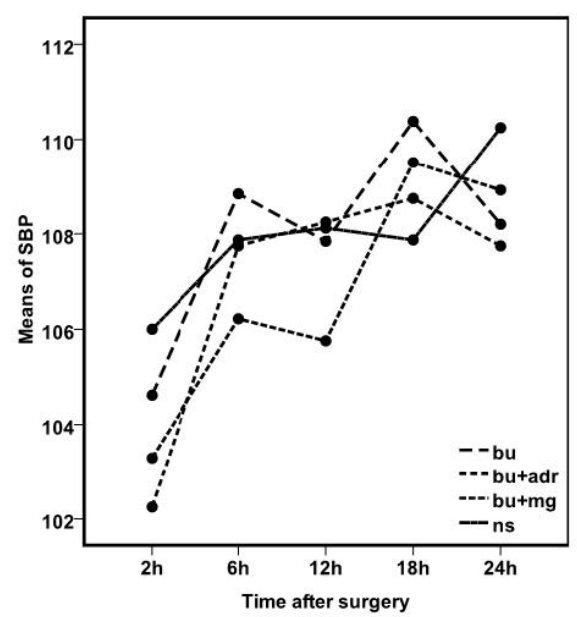

Figure 2. Comparison of Groups in Terms of Systolic Blood Pressure After the Surgery.

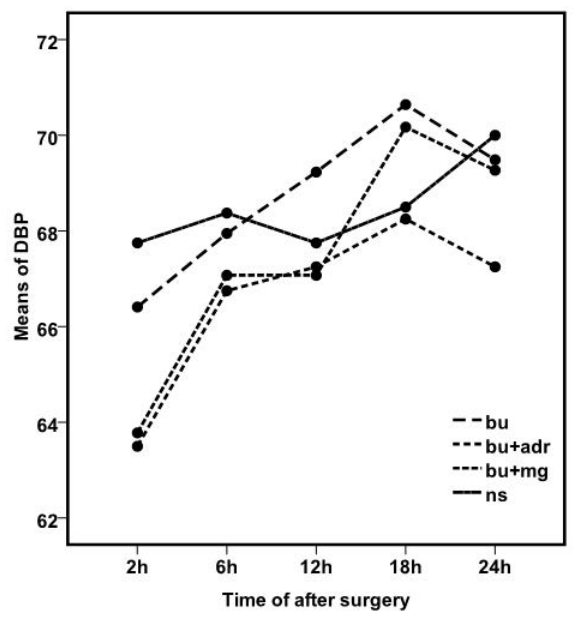

Figure 3. Comparison of Groups in Terms of Diastolic Blood Pressure After the Surgery. and magnesium sulfate combination and all the other groups in terms of the dose of administered analgesic (23).

Koinig et al reported that the intravenous injection of magnesium sulfate before and during a knee arthroscopy significantly reduced the intensity of pain and the dose of analgesic administered 4 hours after the surgery compared to the cases receiving normal saline (24). Rezae et al also found that the intravenous injection of magnesium sulfate before elective cesarean section significantly decreased the intensity of pain and the dose of analgesic administered during the first 24 hours after the surgery (25). Additionally, it reduced postoperative pain, as well as the need to use analgesics after the surgery, which is inconsistent with the results of the current study (13).

In the present study, the intensity of pain and the dose of pethidine administered decreased significantly in the group receiving bupivacaine and adrenaline combination in the first 12 hours after spinal anesthesia compared to the group receiving only bupivacaine. Considering that adrenaline causes the vasoconstriction of the surrounding vessels and given the slower systemic absorption of analgesics, a combination of bupivacaine and adrenaline prolongs analgesia more than the administration of bupivacaine alone. In a similar study by Esmailpour et al, the injection of bupivacaine and adrenaline combination between different layers of the abdominal wall during surgery reduced the intensity of pain and the dose of analgesic administered in the first 12 hours after surgery (on hours 1, 2, and 12 of the surgery) compared to the administration of only bupivacaine, which corroborates the findings of the present study (12). In line with the present study, the study by Niklasson et al showed a reduction in the intensity of pain 12 hours after surgery with the subcutaneous injection of bupivacaine and adrenaline combination. However, no significant differences were observed between this group and the controls receiving normal saline 24 hours after the surgery, which may be due to the effect of adrenaline on drug absorption. There were no differences between the two groups in terms of the dose of analgesic administered in the first 24 hours after the surgery. This contradicts the results of the present study since the administration of analgesics was performed at the patient's request in the above-mentioned 
study while the administration of pethidine was based on the VAS in the current study (26). In the present study, the intensity of pain and the dose of pethidine administered at different times in the group receiving bupivacaine differed significantly from those of the group receiving normal saline, which is in conformity with the results of the study by Tavakoli et al (11).

The study groups were not significantly different in terms of their mean systolic BP in the hours following spinal anesthesia. Rezae et al found a significantly lower mean arterial pressure after the surgery in the group receiving magnesium sulfate, which is not in line with the present findings (25). The disparity of findings may be justified by noting that an increase in BP and HR is a symptom of pain. Moreover, in the study by Rezae et al, the administration of analgesics (Morphine) was performed at the patient's request whereas, in the present study, it was carried out both at the patient's request and based on the VAS. In addition, morphine reduces $\mathrm{BP}$ and $\mathrm{HR}$ more than does pethidine.

\section{Conclusions}

Given that injecting a combination of bupivacaine and magnesium sulfate is an easy technique that requires no special skills or instruments, the researchers propose it as a method of pain relief for women under the cesarean section since it reduces the intensity of pain and the dose of pethidine administered after the surgery.

\section{Conflict of Interests}

Authors declare that they have no conflict of interests.

\section{Financial Support}

This research received no specific grant from funding agencies in the public, commercial, or not-for-profit sectors.

\section{Acknowledgments}

We would like to thank the Vice-president of Research at Babol University of Medical Sciences and the Development Center of Clinical Research of Rouhani Hospital in Babol.

\section{References}

1. Rates of cesarean delivery among Puerto Rican women-Puerto Rico and the U.S. mainland, 1992-2002. MMWR Morb Mortal Wkly Rep. 2006;55(3):68-71.

2. Yazdizadeh B, Nedjat S, Mohammad K, Rashidian A, Changizi N, Majdzadeh R. Cesarean section rate in Iran, multidimensional approaches for behavioral change of providers: a qualitative study. BMC Health Serv Res. 2011; 11:159. doi:10.1186/1472-6963-11-159

3. Chaillet $N$, Dubé $E$, Dugas $M$, et al. Identifying barriers and facilitators towards implementing guidelines to reduce caesarean section rates in Quebec. Bull World Health Organ. 2007;85(10):791-797. doi:10.2471/blt.06.039289

4. Turan A, Karamanlio囚lu B, Memi囚 D, et al. Analgesic effects of gabapentin after spinal surgery. Anesthesiology. 2004;100(4):935-938. doi:10.1097/00000542-20040400000025

5. Lavand'homme P. Postcesarean analgesia: effective strategies and association with chronic pain. Curr Opin
Anaesthesiol. 2006;19(3):244-248.

doi:10.1097/01 aco.0000192815.22989.61

6. DeCherney AH, Pernoll ML. Current Obstetric \& Gynecologic Diagnosis \& Treatment. McGraw-Hill/ Appleton \& Lange; 1994.

7. Bamigboye AA, Hofmeyr GJ. Local anaesthetic wound infiltration and abdominal nerves block during caesarean section for postoperative pain relief. Cochrane Database Syst Rev. 2009(3):CD006954. doi:10.1002/14651858. CD006954. pub2

8. Bamigboye AA, Hofmeyr GJ. Caesarean section wound infiltration with local anaesthesia for postoperative pain relief - any benefit? S Afr Med J. 2010;100(5):313-319.

9. Nguyen NK, Landais A, Barbaryan A, et al. Analgesic Efficacy of Pfannenstiel Incision Infiltration with Ropivacaine $7.5 \mathrm{mg} /$ $\mathrm{mL}$ for Caesarean Section. Anesthesiol Res Pract. 2010;2010. doi:10.1155/2010/542375

10. Shahrzad S, Ghazhani T. Text book Comprehensive official Iranian agents. 3rd ed. Tehran: Taymorzadeh; 2005.

11. Tavakol K, Reiahinegad S, Vahdaniati N. A Study on the Effect of Subcutaneous Injection of Bupivacaine (Marcaine) for Pain Relief after Cesarean. Armaghane Danesh. 2012;17(1):7-13. [Persian].

12. Esmailpour N, Mansour Ghanaie M, Farzi F, Shodjai $H$, Bahrami R, Dalil Heirati SF. The Effect of Intra Abdominal Wall Infiltration with Bupivacaine in Reducing Postoperative Diclofenac Need in Elective Cesarean Sections. Journal of Guilan University of Medical Sciences. 2012;21(81):78-84. [Persian].

13. Kara $H$, Sahin $N$, Ulusan $V$, Aydogdu T. Magnesium infusion reduces perioperative pain. Eur J Anaesthesiol. 2002;19(1):5256. doi:10.1017/s026502150200008x

14. Lysakowski C, Dumont L, Czarnetzki C, Tramèr MR. Magnesium as an adjuvant to postoperative analgesia: a systematic review of randomized trials. Anesth Analg. 2007;104(6):1532-1539, table of contents. doi:10.1213/01. ane.0000261250.59984. $\mathrm{cd}$

15. Kundra S, Singh RM, Singh G, Singh T, Jarewal V, Katyal S. Efficacy of Magnesium Sulphate as an Adjunct to Ropivacaine in Local Infiltration for Postoperative Pain Following Lower Segment Caesarean Section. J Clin Diagn Res. 2016;10(4):UC18-22. doi:10.7860/ jcdr/2016/17119.7683

16. Larsen KR, Kristensen BB, Rasmussen MA, et al. Effect of high-volume systematic local infiltration analgesia in Caesarean section: a randomised, placebo-controlled trial. Acta Anaesthesiol Scand. 2015;59(5):632-639. doi:10.1111/ aas.12509

17. Razavi SS, Peyvandi H, Badrkhani Jam AR, Safari F, Teymourian $\mathrm{H}$, Mohajerani SA. Magnesium Versus Bupivacaine Infiltration in Controlling Postoperative Pain in Inguinal Hernia Repair. Anesth Pain Med. 2015;5(6):e30643. doi:10.5812/ aapm.30643

18. Dashe JS, Bloom SL, Spong CY, Hoffman BL. Williams Obstetrics. McGraw Hill Professional; 2018.

19. Miller RD, Eriksson LI, Fleisher LA, Wiener-Kronish JP, Cohen $\mathrm{NH}$, Young WL. Miller's Anesthesia E-Book. Elsevier Health Sciences; 2014.

20. Pardo M, Miller RD. Miller Anesthesia. 7th ed. New York: Elsevier Health Sciences; 2010: 1640-3.

21. Eldaba AA, AmrYM, Sobhy RA. Effect of wound infiltration with bupivacaine or lower dose bupivacaine/ magnesium versus placebo for postoperative analgesia after cesarean section. Anesth Essays Res. 2013;7(3):336-340. doi:10.4103/02591162.123227

22. Tauzin-Fin P, Sesay M, Svartz L, Krol-Houdek MC, Maurette P. Wound infiltration with magnesium sulphate and ropivacaine 
mixture reduces postoperative tramadol requirements after radical prostatectomy. Acta Anaesthesiol Scand. 2009;53(4):464-469. doi:10.1111/j.1399-6576.2008.01888.x

23. Lee AR, Yi HW, Chung IS, et al. Magnesium added to bupivacaine prolongs the duration of analgesia after interscalene nerve block. Can J Anaesth. 2012;59(1):21-27. doi:10.1007/s12630-011-9604-5

24. Koinig H, Wallner T, Marhofer P, Andel H, Horauf K, Mayer N. Magnesium sulfate reduces intra- and postoperative analgesic requirements. Anesth Analg. 1998;87(1):206-210. doi:10.1097/00000539-199807000-00042
25. Rezae M, Naghibi K, Taefnia AM. Effect of pre-emptive magnesium sulfate infusion on the post-operative pain relief after elective cesarean section. Adv Biomed Res. 2014;3:164. doi:10.4103/2277-9175.139127

26. Niklasson B, Borjesson A, Carmnes UB, Segerdahl M, Ohman SG, Blanck A. Intraoperative injection of bupivacaineadrenaline close to the fascia reduces morphine requirements after cesarean section: a randomized controlled trial. Acta Obstet Gynecol Scand. 2012;91(12):1433-1439. doi:10.1111/ j.1600-0412.2012.01480.x

C 2021 The Author(s); This is an open-access article distributed under the terms of the Creative Commons Attribution License (http:// creativecommons.org/licenses/by/4.0), which permits unrestricted use, distribution, and reproduction in any medium, provided the original work is properly cited. 